\title{
INFLUENCE OF NON-PLASTIC FINES ON THE RESPONSE OF A SILTY SAND TO CYCLIC LOADING
}

\author{
H. K. DASH ${ }^{\mathrm{i})}$, T. G. Sitharam ${ }^{\mathrm{ii})}$ and B. A. BAUDET ${ }^{\mathrm{iii}}$
}

\begin{abstract}
Data from cyclic loading tests on sand-fine mixtures made of Ahmedabad sand and quarry dust are presented. Tests were performed at constant void ratio, constant relative density and constant sand skeleton void ratio, for a variety of fines contents. Instead of looking at the direct effect of fines content on the cyclic response of the sand-fine mixtures, a novel approach of analysing the cyclic test data is proposed, by normalising these data with respect to state. The important difference with other similar work on plain sand is that the reference line for normalising must take account of the fines content. Simple definitions of equivalent void ratio, which take account of fines content, have been used. The results presented indicate that state plays an important role in defining the cyclic resistance ratio and pore water pressure generation during cyclic loading.
\end{abstract}

Key words: cyclic resistance, limiting fines content, liquefaction, pore water pressure generation, sand, state parameter (IGC: D7)

\section{INTRODUCTION}

The presence of fines in sand will affect its behaviour both under monotonic loading (Yamamuro and Lade, 1997; Lade and Yamamuro, 1997; Vaid et al., 1999; Yamamuro and Kovert, 2001; Hyodo et al., 2002; Haeri and Hamidi, 2005; Brandon et al., 2006; Ravishankar, 2006; Monkul and Ozden, 2006; Dash, 2008) and cyclic loading (Amini and Qi, 2000; Thevanayagam, 2000; Polito and Martin, 2001; Xenaki and Athanasopoulos, 2003; Ravishankar, 2006; Sadek and Saleh, 2007; Dash, 2008; Dash and Sitharam, 2009). It was generally thought that fines help resist liquefaction (Xenaki and Athanasopoulos, 2003), until large scale liquefactionrelated failures were found to occur in silty sand deposits, for example during the recent earthquake in Bhuj, India, in 2001. Since then, the behaviour, and specifically the liquefaction of silty sands and sand-silt mixtures have been studied extensively.

The presence of non-plastic fines typically affects the location of the Normal Compression Line (e.g., Coop and Atkinson, 1993; Nocilla et al., 2006). Thevanayagam and Mohan (1998) proposed that accounting for the fines when determining void ratio can help unify the behaviour of sands with different fines contents. So when the fines content is low enough that the behaviour of the soil is governed by the host sand behaviour, fines can be count- ed as void and a sand skeleton void ratio, $e_{s}$, can be defined;

$$
e_{\mathrm{s}}=\frac{e+F C}{1-F C}
$$

for a silty sand of void ratio $e$, and fines content FC (Kenny, 1977; Kuerbis et al., 1988). When the fines content is high enough that the behaviour of the soil is governed by the fines matrix behaviour, the host sand grains can be counted as void, and an interfine void ratio, $e_{\mathrm{f}}$, can be defined;

$$
e_{\mathrm{f}}=\frac{e}{F C}
$$

The addition of fines to sand will result in a different grading and void ratio, and researchers have traditionally tried to maintain either the void ratio $(e)$, or the relative density $(R D)$, or the sand skeleton void ratio $\left(e_{s}\right)$, constant in their research (e.g., Polito and Martin, 2001; Sadek and Saleh, 2007). This allowed the effect of fines content to be isolated and used as sole variable. Many studies concurred that for a given host sand there is a limiting fines content (LFC) which constitutes a threshold when the soil behaviour moves from being governed by the coarse (sand) particles to being dominated by the fines matrix. Of the different methods proposed to calculate the LFC, we will adopt the one used by Hazirbaba (2005),

i) PhD, Reader, Department of Civil Engineering, College of Engineering and Technology (CET), Biju Patnaik University of Technology (BPUT), India.

ii) $\mathrm{PhD}$, Professor, Department of Civil Engineering, Indian Institute of Science, India.

iii) PhD, Lecturer, Department of Civil Engineering, University of Hong Kong, Hong Kong, (formerly University College London) (baudet@ hku.hk).

The manuscript for this paper was received for review on July 14, 2009; approved on August 5, 2010.

Written discussions on this paper should be submitted before May 1, 2011 to the Japanese Geotechnical Society, 4-38-2, Sengoku, Bunkyo-ku, Tokyo 112-0011, Japan. Upon request the closing date may be extended one month. 
defined as;

$$
L F C=\frac{G_{\mathrm{f}} e_{\mathrm{s}}}{G_{\mathrm{f}} e_{\mathrm{s}}+G_{\mathrm{s}}\left(1+e_{\mathrm{f}}\right)}
$$

Where $G_{\mathrm{f}}$ and $e_{\mathrm{f}}$ represent the specific gravity and maximum void ratio of the fines, and $G_{\mathrm{s}}$ and $e_{\mathrm{s}}$ represent the specific gravity and maximum void ratio of the sand.

The effects of non-plastic fines on the monotonic behaviour of sand are increasingly understood, however there is still no consensus on how non-plastic fines may affect the cyclic behaviour of silty sands. For example, for tests carried out at constant void ratio (CVR) on sands of different origins, the cyclic resistance ratio, CRR, defined as the cyclic stress ratio required to cause liquefaction after a certain cycle of loading (Youd et al., 2001), was found to increase with increasing fines content by Chang et al. (1982) and Amini and Qi (2000), to decrease with increasing fines content by Kuerbis et al. (1988) and Finn et al. (1994), but to decrease for fines contents less than the limiting fines content and increase for fines contents larger than the LFC by Polito and Martin (2001), Xenaki and Athanasopoulos (2003), Ueng et al. (2004) and Ravishankar (2006). Keeping the void ratio constant while increasing the fines content implies an increase or a decrease or an initial decrease followed by an increase in the density of the sand-silt mixture, which may influence the result. A comparative study of the effects of non-plastic fines on the cyclic resistance of Ottawa sand by Sadek and Saleh (2007) showed that the cyclic resistance of sandy soils is better understood using a constant relative density (CRD) approach, if the fines content is below the limiting fines content, and a constant void ratio approach if the fines content is beyond the limiting fines content.

The constant relative density approach has been adopted by several researchers, but results are rather conflicting. For example, Singh (1994) found that at constant relative density, the cyclic resistance ratio decreases with increasing fines content, while Polito and Martin (2001) found that the cyclic resistance ratio remains constant for values of fines content up to the LFC, after which it drops to a stable value about half of the initial CRR. Finally, Sadek and Saleh (2007) found that the cyclic resistance ratio initially increases up to a particular silt content, after which it decreases with increasing fines content.

Researchers have also tried adopting a constant sand skeleton void ratio approach (CSSVR) in order to unify results, but again published data are conflicting. For example, Kuerbis et al. (1988), Vaid (1994), and Xenaki and Athanasopoulos (2003) found an increase in cyclic resistance with increasing fines content. A similar result was obtained by Polito and Martin (2001) using Yatesville sand as host sand, but they found that the cyclic resistance ratio reached a plateau with increasing fines content when they tested Monterey sand. A constant plateau was also found by Finn et al. (1994). Based on the conceptual framework proposed by Thevanayagam and Mohan (1998), Xenaki and Athanasopoulos (2003) carried out tests at constant interfine void ratio, $e_{\mathrm{f}}$, using sand-silt mixtures with fines content larger than the limit- ing fines content. They found a decrease in cyclic resistance with increasing fines content.

The generation of pore water pressure during cyclic loading has the effect of reducing the soil strength and can lead to liquefaction. The pioneering work of Lee and Albaisa (1974) on sands of different origins has shown that values of maximum pore water pressure generated during cyclic loading are within a narrow band when normalized by the confining pressure and plotted against the cycle ratio $N / N_{\mathrm{L}}$, independently of the confining pressure or of the relative density of the specimens. Erten and Maher (1995) and Polito (1999) found similarly narrow bands for mixtures of sand with non-plastic or low plasticity fines, independently of the fines content. These narrow bands are somewhat expected since at cycle $N=0$ there is no generated pore water pressure, and when liquefaction is reached, the pore water pressure is equal to the confining pressure, which occurs when $N=N_{\mathrm{L}}$. The band in between may then be partly consequence of the scatter between different responses of similar shape between these two points, and while it is a useful indication of pore water pressure generated during cyclic loading in sand, it is quite approximate. A novel approach was proposed by Qadimi and Coop (2007), who used a stress state parameter to normalise the pore water pressure generated during cyclic tests on Dog's Bay carbonate sand from different initial states ranging from normally consolidated to lightly over-consolidated. The normalisation allowed to identify distinct pore water responses for different initial states at the start of cyclic loading, therefore marking a significant improvement in the quantification of pore water pressure generation and prediction of liquefaction. This paper attempts to show that applying a similar approach to sand-fines mixtures can also help refine design charts for the cyclic response of silty sands.

\section{TESTING MATERIALS}

The study consisted of triaxial tests carried out on mixtures of "clean" Ahmedabad sand with different amounts of non-plastic fines. The Ahmedabad sand was collected from excavated pits close to the Sabarmati river belt, an area of Ahmedabad which suffered extensive damage during the 2001 Bhuj earthquake. This quartzitic sand is poorly graded, with a mean grain size $D_{50}=0.29$ $\mathrm{mm}$. The silt portion was removed from the sand by wet sieving the original Ahmedabad sand using a $75 \mu \mathrm{m}$ Indian Standard sieve, so as to obtain "clean"' sand. The particle distribution of the sand before and after sieving is shown in Fig. 1. Non-plastic quarry dust was used as a substitute for the silt in the sand-silt mixtures. It was sourced from the fine grained $(<75 \mu \mathrm{m})$ portion of quarry dust produced by aggregate crusher plants in and around Bangalore, India. The particle size distribution of the silt is shown also in Fig. 1. Characteristics of the clean Ahmedabad sand and quarry dust, determined following Indian Standard IS: 2720 (part-3)-1980 and IS: 2720 (part-14)-1983, are given Table 1.

The sand-silt mixtures were prepared by adding the 
quarry dust to the clean sand in different proportions in weight, varying between $5 \%$ and $75 \%$, and mixing until they became uniform. The pure silt and pure clean sand were also tested. The maximum and minimum gross void ratios of the sand-silt mixtures were determined; they are plotted in Fig. 2 as a function of fines content. The limiting fines content, LFC, was determined according to Eq. (3) as about $20 \%$.

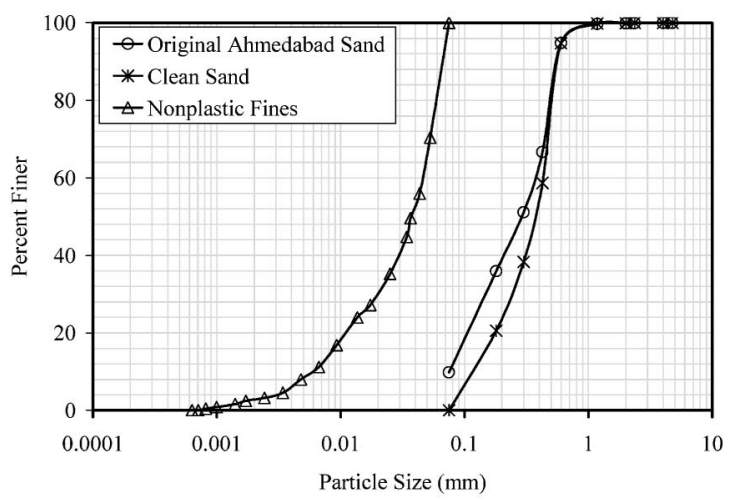

Fig. 1. Particle size distribution of host sand and non-plastic fines

Table 1. Index properties of host sand and silt

\begin{tabular}{l|c|c}
\hline \multicolumn{1}{c|}{ Soil Type } & $\begin{array}{c}\text { Clean } \\
\text { Ahemadabad } \\
\text { Sand (host sand) }\end{array}$ & $\begin{array}{c}\text { Quarry Dust } \\
\text { (silt) }\end{array}$ \\
\hline IS Classification Symbol & $\mathrm{SP}$ & $\mathrm{ML}$ \\
\hline Maximum Grain Size $(\mathrm{mm})$ & 2 & 0.0747 \\
\hline Mean Grain Size $(\mathrm{mm})$ & 0.375 & 0.037 \\
\hline Minimum Grain Size $(\mathrm{mm})$ & 0.075 & 0.00063 \\
\hline Uniformity Coefficient $\left(C_{\mathrm{u}}\right)$ & 3.58 & 7.83 \\
\hline Coefficient of Gradation $\left(C_{\mathrm{z}}\right)$ & 1.163 & 1.418 \\
\hline Specific Gravity $\left(G_{\mathrm{s}}\right)$ & 2.65 & 2.67 \\
\hline Minimum Index Density $\left(\mathrm{kN} / \mathrm{m}^{3}\right)$ & 15.77 & 10.14 \\
\hline Maximum Index Density $\left(\mathrm{kN} / \mathrm{m}^{3}\right)$ & 18.66 & 16.16 \\
\hline Minimum Index Void Ratio $\left(e_{\min }\right)$ & 0.42 & 0.652 \\
\hline Maximum Index void Ratio $\left(e_{\max }\right)$ & 0.68 & 1.632 \\
\hline
\end{tabular}

\section{SAMPLE PREPARATION AND TESTING PROCEDURE}

A series of monotonic and cyclic triaxial tests was performed on the sand-silt mixtures. Not all the tests have been reported here, and only those used for the main analyses are described in Tables 2 and 3. The specimens, of $50 \mathrm{~mm}$ diameter and $100 \mathrm{~mm}$ length, were formed by dry deposition of the oven-dried material (ASTM D 5311). The dense specimens were prepared in five layers, tamping each layer so as to achieve the required density. The relative density at tamping was increased by $1 \%$ per layer to obtain a final density that was throughout the specimen. The loose specimens were prepared by raising a 12 $\mathrm{mm}$ diameter funnel along the axis of symmetry of the mould, and allowing minimal drop height. A positive

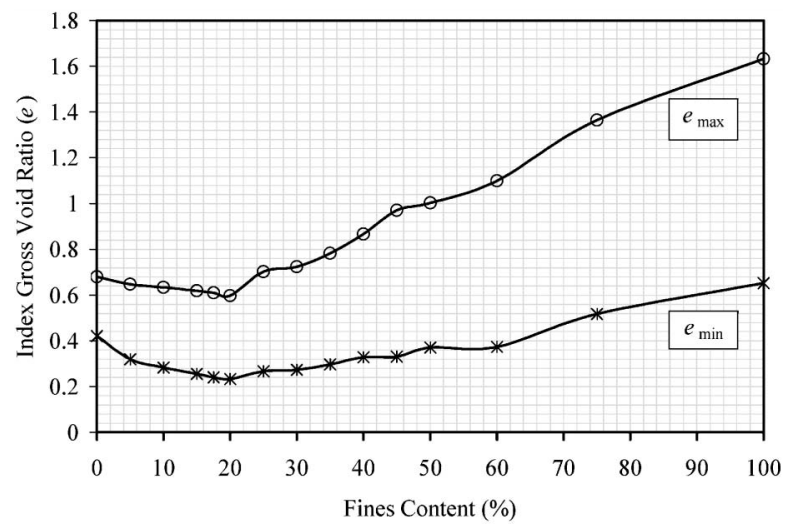

Fig. 2. Variation of index gross void ratio with fines content

Table 3. Detail of monotonic undrained tests used in the analyses

\begin{tabular}{c|c|l|c}
\hline Test Type & $\begin{array}{c}\text { CVR }(e) / C R D(\%) / \\
\text { CSSVR }\left(e_{\mathrm{s}}\right)\end{array}$ & \multicolumn{1}{c}{ Soil Type } & $\begin{array}{c}\sigma_{3 \mathrm{c}}^{\prime} \\
(\mathrm{kPa})\end{array}$ \\
\hline CVR & $e=0.44$ & $\begin{array}{l}\text { clean sand }+0,10, \\
20,30,40,50 \% \text { silt }\end{array}$ & 100 \\
\hline CVR & $e=0.54$ & $\begin{array}{l}\text { clean sand }+0,10,20, \\
30,40,50 \% \text { silt }\end{array}$ & 100 \\
\hline CRD & $\mathrm{RD}=54 \%$ & $\begin{array}{l}\text { clean sand }+0,10,20,50 \% \text { silt } \\
30,40,50\end{array}$ & 100 \\
\hline CSSVR & $e_{\mathrm{s}}=0.607$ & $\begin{array}{l}\text { clean sand }+0,10, \\
20 \% \text { silt }\end{array}$ & 100 \\
\hline CSSVR & $e_{\mathrm{s}}=0.85$ & clean sand $+20 \%$ silt & 100 \\
\hline
\end{tabular}

Table 2. Detail of cyclic tests used in the analyses

\begin{tabular}{c|c|c|c|c|c}
\hline Test Type & $\begin{array}{c}\text { CVR }(e) / \text { CRD }(\%) / \\
\text { CSSVR }\left(e_{s}\right)\end{array}$ & Soil Type & $\begin{array}{c}\sigma_{3 c}^{\prime} \\
(\mathrm{kPa})\end{array}$ & $\begin{array}{c}\text { Freq } \\
(\mathrm{Hz})\end{array}$ & $\begin{array}{c}\text { Range of Cyclic } \\
\text { Stress Ratio (CSR) }\end{array}$ \\
\hline CVR & $e=0.44$ & clean sand $+0,10,20,30,40,50 \%$ silt & 100 & 0.1 & 0.154 \\
\hline CVR & $e=0.54$ & clean sand $+0,10,20,30,40,50 \%$ silt & 100 & 0.1 & 0.128 \\
\hline CRD & $\mathrm{RD}=54 \%$ & clean sand $+0,10,20,30,40,50 \%$ silt & 100 & 0.1 & 0.128 \\
\hline CSSVR & $e_{\mathrm{s}}=0.607$ & clean sand $+0,10,20 \%$ silt & 100 & 0.1 & 0.154 \\
\hline CSSVR & $e_{\mathrm{s}}=0.85$ & clean sand $+20 \%$ silt & 100 & 0.1 & 0.154 \\
\hline
\end{tabular}


effective stress was applied to the specimens prior to cycling through a $20 \mathrm{kPa}$ vacuum. Saturation was achieved by passing $\mathrm{CO}_{2}$ slowly through the specimen, followed by de-aired water. The back pressure was then increased while maintaining the effective confining pressure at $30-35 \mathrm{kPa}$ until a B-value of 0.95 or more was obtained. Several tests were repeated to confirm the results.

The monotonic and cyclic tests were carried out using a triaxial apparatus where both stress and strain controlled tests could be performed. Frequencies between $0.1 \mathrm{~Hz}$ and $10 \mathrm{~Hz}$, using sine, triangular and square wave forms, could be applied for the dynamic loading. The vertical deformations were measured using a $50 \mathrm{~mm}$ LVDT of $0.01 \mathrm{~mm}$ resolution. The pore water pressure was monitored using a transducer of maximum capacity $1 \mathrm{MPa}$ with a resolution $1 \mathrm{kPa}$. Volume change during consolidation was measured by a purpose-built device with a resolution $0.01 \mathrm{ml}$ and a maximum capacity of $50 \mathrm{ml}$. No membrane penetration correction could be made because all tests were undrained. However, given that the material tested was a silty sand, with the fines filling the voids, and that the pressures applied were low, membrane penetration should not have affected the data. A submersible 5 $\mathrm{kN}$ load cell measured the deviatoric load.

The specimens were isotropically consolidated to the desired effective stress before shearing started. The void

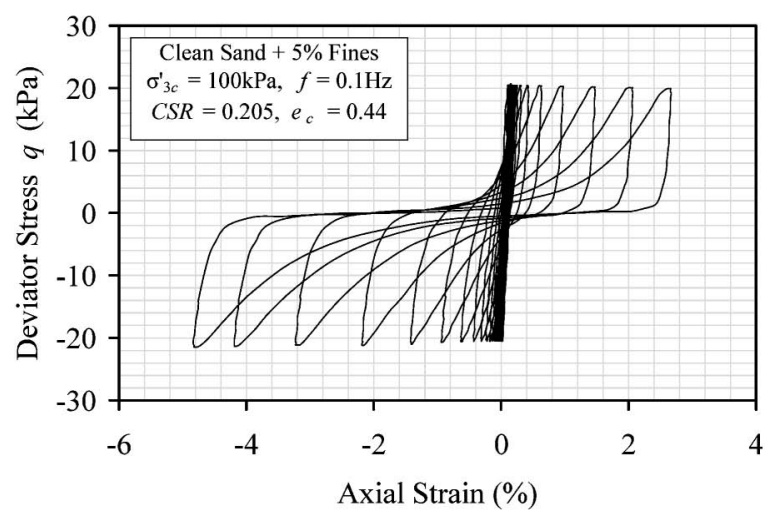

(a)

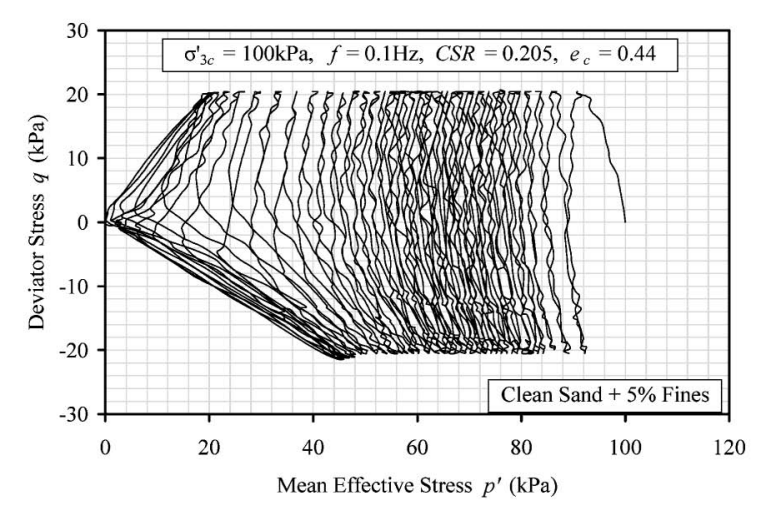

(b)

Fig. 3. Cyclic loading for a specimen prepared at a gross void ratio $e_{\mathrm{c}}$ $=0.44$ and tested with a cyclic stress ratio $C S R=0.205$ : (a) stressstrain response, (b) stress paths ratios reported here as "initial void ratios" are the values of void ratio calculated post-consolidation from the volume changes measured during consolidation $\left(e_{\mathrm{c}}\right.$ in the figures). Monotonic undrained tests, performed straincontrolled with an axial strain rate of $0.6 \mathrm{~mm} / \mathrm{min}$, provided a reference behaviour, in particular the Critical State Line (CSL) used later for normalising. The cyclic tests were performed at different cyclic stress ratios, where the cyclic stress ratio (CSR) is defined as;

$$
C S R=\frac{\sigma_{\mathrm{dc}}}{\sigma_{3 \mathrm{c}}^{\prime}}
$$

With the cyclic stress, $\sigma_{\mathrm{dc}}$, defined as the stress resulting from the peak cyclic load in compression $\left(\Delta P_{\mathrm{c}}\right)$ and extension $\left(\Delta P_{\mathrm{e}}\right)$ applied on the specimen of area $A_{\mathrm{c}}$ postconsolidation;

$$
\sigma_{\mathrm{dc}}=\frac{\Delta P_{\mathrm{c}}+\Delta P_{\mathrm{e}}}{A_{\mathrm{c}}}
$$

Liquefaction was assumed to have been reached when the effective stress on the specimen became equal to zero as a result of the excess pore water pressure becoming equal to the applied confining pressure. The cyclic resistance ratio (CRR) was defined as the cyclic stress ratio at which the number of cycles required to reach liquefaction $\left(N_{\mathrm{L}}\right)$ is 20 . For each fines content a minimum of three cyclic tests

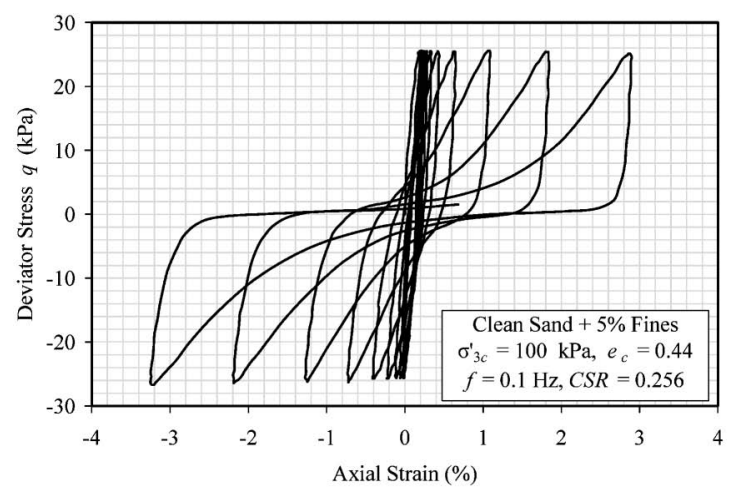

(a)

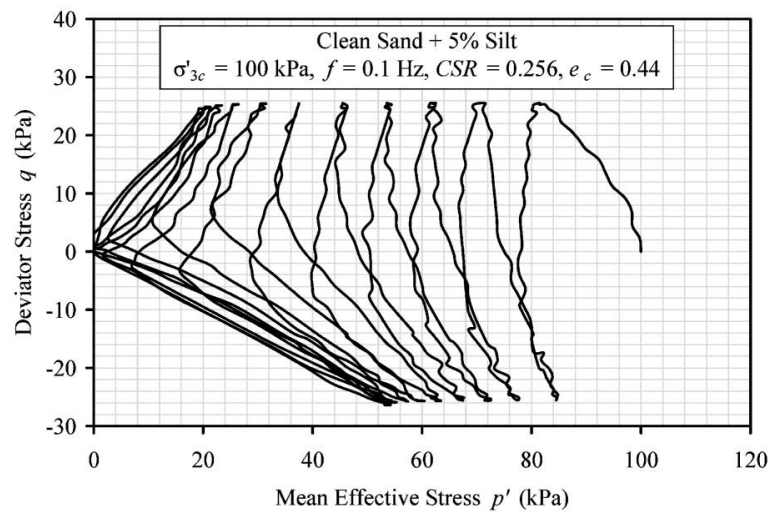

(b)

Fig. 4. Cyclic loading for a specimen prepared at a gross void ratio $e_{\mathrm{c}}$ $=0.44$ and tested with a cyclic stress ratio $C S R=0.256$ : (a) stressstrain response, (b) stress paths 


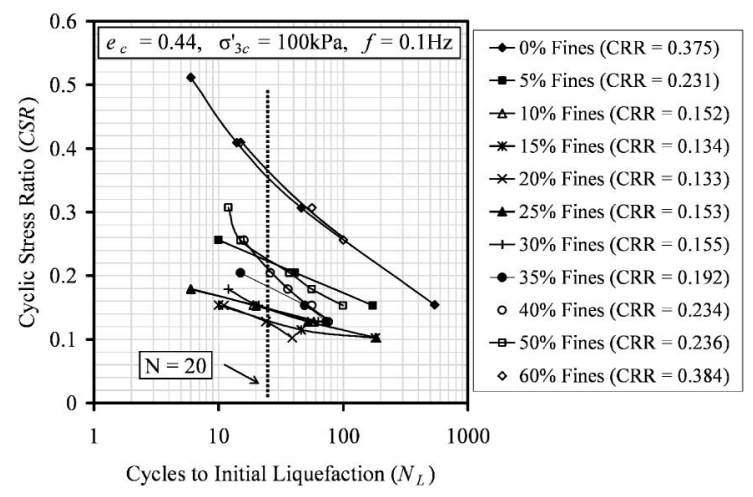

Fig. 5. Determination of cyclic resistance ratio (CRR) for specimens prepared at a gross void ratio $e_{\mathrm{c}}=0.44$

were performed at different cyclic stress ratios and the number of cycles required to reach liquefaction was recorded. Typical stress paths obtained during cyclic loading are shown in Figs. 3(a) and 4(a) for specimens containing 5\% fines content which were tested at constant gross void ratios of 0.44 under $100 \mathrm{kPa}$ confining pressure, with cyclic stress ratios equal to 0.205 and 0.256 respectively, and a frequency of $0.1 \mathrm{~Hz}$. The values of CSR were then plotted against the number of cycles to liquefaction; an example is given in Fig. 5 for specimens tested at a gross void ratio 0.44 which were tested under $100 \mathrm{kPa}$ confining pressure at a frequency of $0.1 \mathrm{~Hz}$. The cyclic resistance ratio (CRR) was taken as the cyclic stress ratio for which liquefaction was obtained at 20 cycles of uniform loading. This represents an earthquake of magnitude equal to 7.5 similar to the one that occurred in Bhuj, India, in 2001. For some tests, the number of cycles $N=20$ coincided with the point where the double amplitude strain reached $5 \%$, which is also a recognized definition of liquefaction (ASTM D 5311).

\section{CRITICAL STATES OF SILTY AHMEDABAD SAND}

A series of monotonic undrained compression tests was performed on sand-fines mixtures containing between $0 \%$ and $75 \%$ fines. Several tests were performed for each mixture, mostly under $100 \mathrm{kPa}$ confining pressure, with varying initial (post-consolidation) void ratios. Figures 6 and 7 show examples of stress-strain response and stress paths in specimens with varying fines contents which were tested at constant void ratios of 0.44 and 0.54 respectively, under $100 \mathrm{kPa}$ confining pressure. In Fig. 8, the points obtained at the end of shearing have been plotted in the volumetric plane $e-\ln p^{\prime}$. From Figs. 6 and 7, most specimens had reached stable stress and volume conditions at the end of the tests. The Critical State Lines (CSLs) determined for the different fines contents appear to plot separately, with increasing slope and intercept as the fines content increases. The same has been found in the past for the Normal Compression Lines of sand-fines mixtures (e.g., Martins et al., 2001; Monkul and Ozden, 2006; Nocilla et al., 2006).

The normalisation proposed by Thevanayagam and

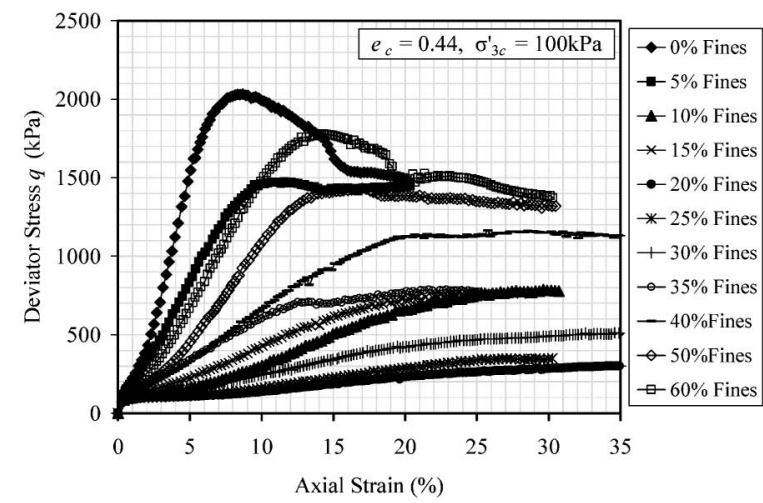

(a)

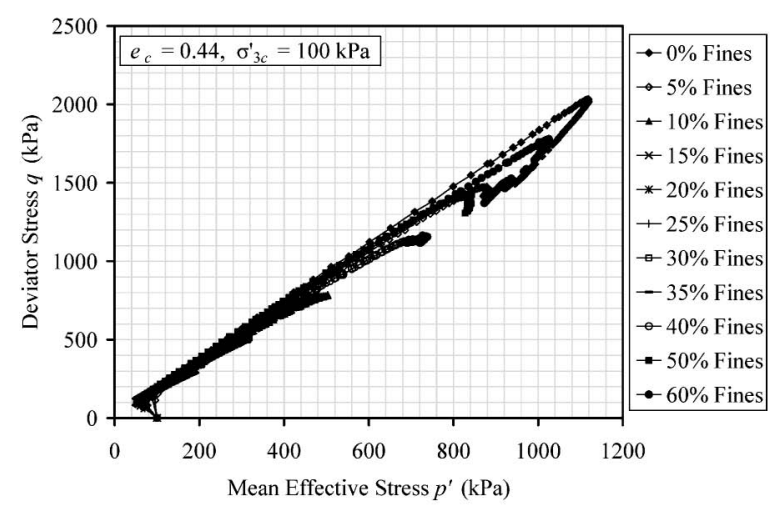

(b)

Fig. 6. Monotonic loading for a specimen prepared at a gross void ratio $e_{\mathrm{c}}=0.44$ and tested at a confining pressure $100 \mathrm{kPa}$ : (a) stressstrain response, (b) stress paths

Mohan (1998) was applied to the void ratios measured at the end of the tests: Equation (1) was used to calculate the sand skeleton void ratio of the specimens with fines contents less than or equal to $20 \%$, while Eq. (2) was used to calculate the interfine void ratio of the specimens with fines contents higher than the limiting fines content. The sand skeleton void ratio and the interfine void ratio constitute equivalent void ratios that take account of the presence of the fines in the sand. Figure 9(a) presents the data for lower fines contents, plotted as sand skeleton void ratio, $e_{\mathrm{s}}$, against the natural logarithm of the mean effective stress, ln $p^{\prime}$, and Fig. 9(b) presents the data for the higher fines contents, plotted as interfine void ratio, $e_{\mathrm{f}}$, against $\ln p^{\prime}$. A small scatter is noticeable, attributed to the rather unrefined normalisation applied, however there seems to be a convergence to a single line in either graph. With the pure sand data as reference, and particularly the data at larger stresses where it is thought that the critical state points have reached the linear part of the CSL, a fitting line has been drawn in Fig. 9(a). The same line was drawn in Fig. 9(b), which more or less also fits these data. In this study, the full range of fines contents is of interest, therefore it was attempted to plot all data on a single graph, showing an equivalent void ratio, $e_{\text {equiv }}$, against $\ln p^{\prime}$ (Fig. 10). The equivalent void ratio takes the definition of $e_{\mathrm{s}}$ when the fines content is less than or equal 


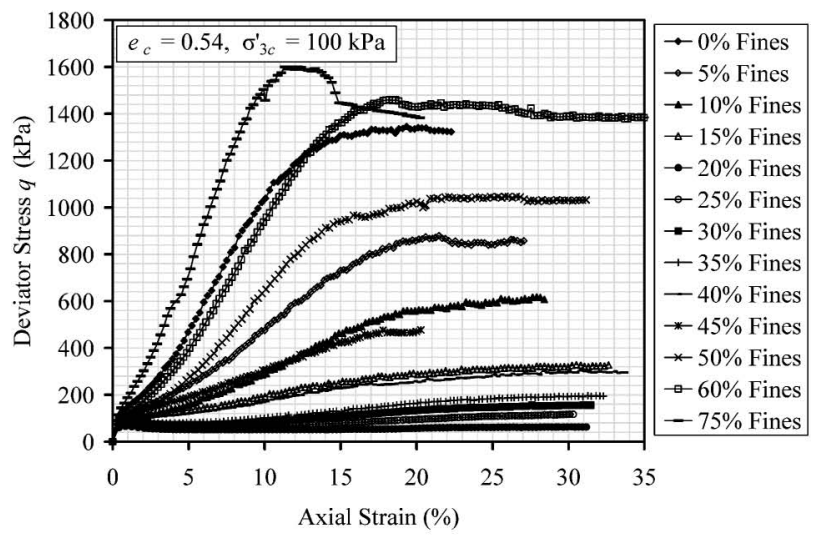

(a)

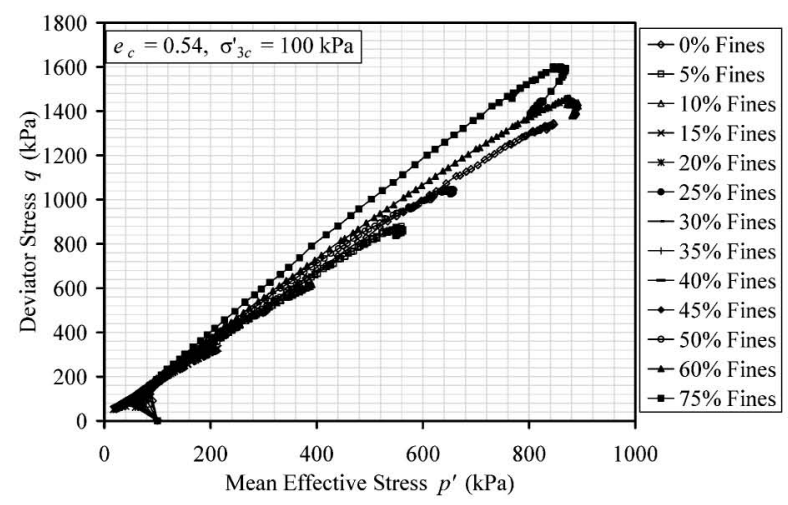

(b)

Fig. 7. Monotonic loading for a specimen prepared at a gross void ratio $e_{\mathrm{c}}=0.54$ and tested at a confining pressure $100 \mathrm{kPa}$ : (a) stressstrain response, (b) stress paths

to $20 \%$ and that of $e_{\mathrm{f}}$ when it is higher;

$$
\begin{aligned}
& e_{\text {equiv }}=\frac{e+F C}{1-F C} \text { when the fines content } \mathrm{FC} \leq \mathrm{LFC} \\
& e_{\text {equiv }}=\frac{e}{F C} \quad \text { when the fines content } \mathrm{FC}>\mathrm{LFC}
\end{aligned}
$$

A point of singularity is noticed as at the limiting fines content the definitions do not satisfy $e_{\mathrm{s}}=e_{\mathrm{f}}$, but the limited scatter seems to indicate that to assemble both sets of data on the same graph is not unreasonable. The fitted line defined above is also shown: it represents a unique normalised CSL for all sand-fine mixtures, and will be used in the following as reference line for normalising.

\section{NORMALISATION OF CYCLIC BEHAVIOUR}

The importance of state on the behaviour of soil has been demonstrated in many studies (e.g., Wroth and Bassett, 1965; Been and Jefferies, 1985; Coop and Lee, 1993). It is either defined in terms of volume or in terms of stress. Because of the uncertainties associated with the shape of the Critical State Lines at low stresses, it was chosen to adopt the same approach as for example Coop and Lee (1993), Klotz and Coop (2001), and Qadimi and Coop (2007), where the state is quantified by the horizon-

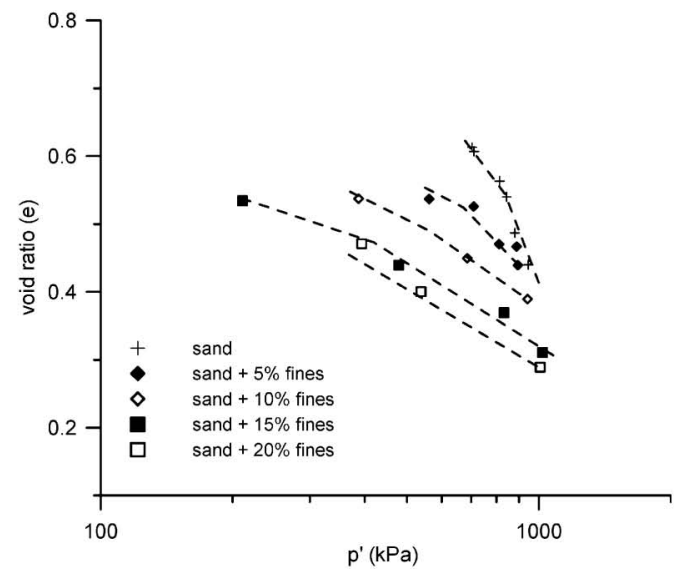

(a)

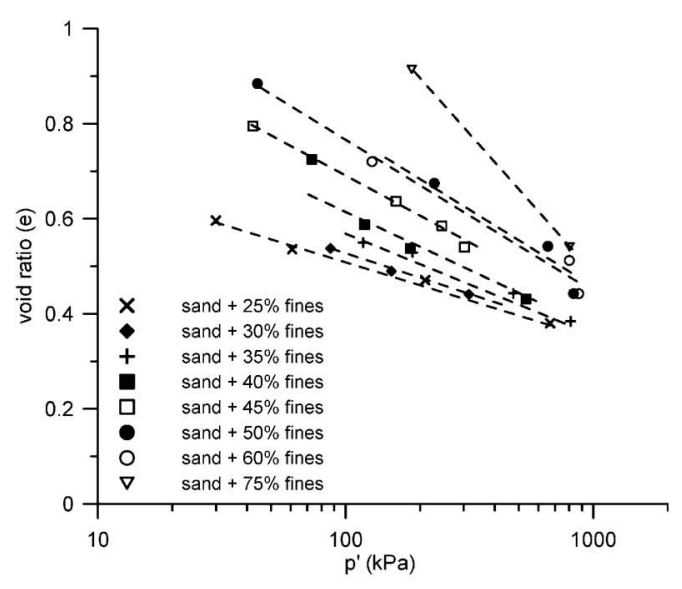

(b)

Fig. 8. End of test and critical state points of sand-fine mixtures from monotonic undrained triaxial compression tests: (a) fines content less than the LFC, (b) fines content above the LFC

tal distance between the current stress state and a reference line. In our study, we have adopted the normalised Critical State Line determined in Fig. 10 as reference line. This implies that the initial stress state for each test will simply be represented by the horizontal distance of the stress point at the start of shearing to the normalised Critical State Line, and expressed as $p^{\prime} / p_{\mathrm{cs}}^{\prime}$, where $p_{\mathrm{cs}}^{\prime}$ is the equivalent pressure on the normalised CSL (see Fig. 8). Figure 11 shows the initial (post-consolidation) states for the tests carried out at a cyclic stress ratio $\mathrm{CSR}=0.128$ in the normalised plot, $e_{\text {equiv }}-\ln p^{\prime}$ (Fig. 11(a)). The values of the stress state parameter, $p^{\prime} / p_{\mathrm{cs}}^{\prime}$, are shown in bold next to the points on the graph. Similarly, Fig. 11(b) shows the initial states for the tests carried out at a cyclic stress ratio $\mathrm{CSR}=0.154$ and the initial stress state parameters. It is clear that points lying on a line parallel to the normalised CSL will have the same value of $p^{\prime} / p_{\mathrm{cs}}^{\prime}$, so that a set of parallel lines can be drawn that represent contours of values of stress state parameter. In that way, the normalised CSL coincides with a contour 1.00, while other parallel lines to the left of it represent values of stress state parameter less than 1.00. Here because the 


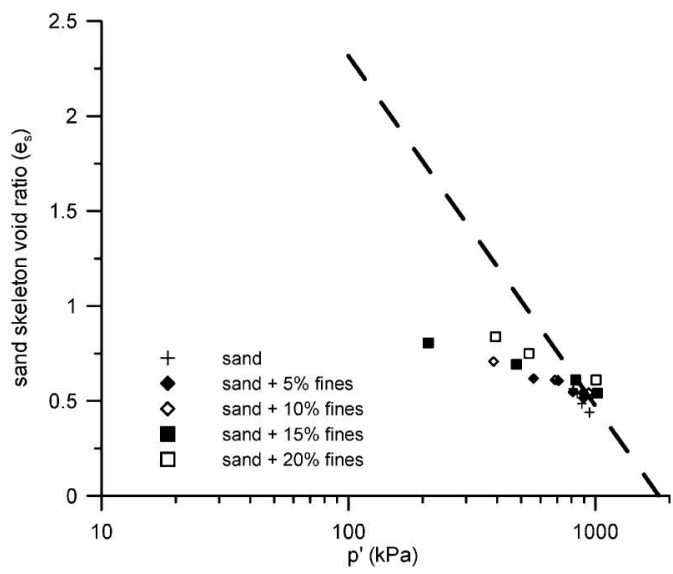

(a)

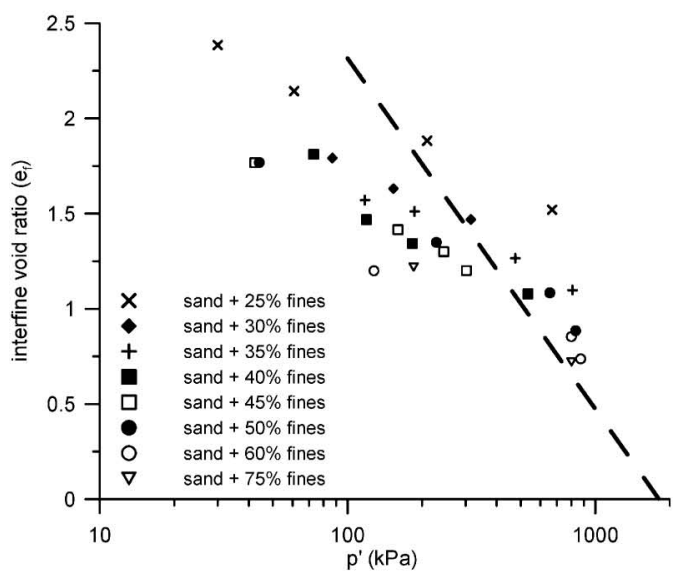

(b)

Fig. 9. End of test and critical state points of sand-fine mixtures from monotonic undrained triaxial compression tests, in plots of normalised void ratio against $\ln p^{\prime}$ : (a) mixtures with fines contents less than the LFC, (b) mixtures with fines contents more than the LFC

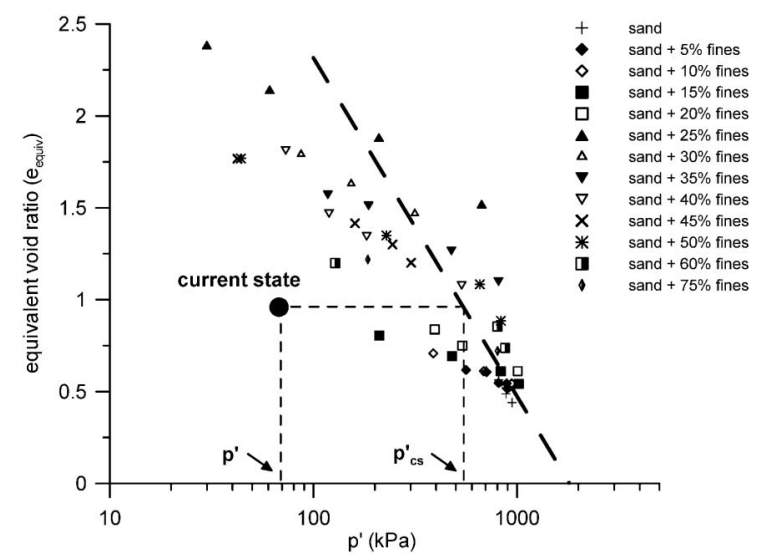

Fig. 10. Definition of stress state parameter $p^{\prime} / p_{\mathrm{cs}}^{\prime}$ in plot of void ratio against $\ln p^{\prime}$

specimens were all sheared from low stresses, their initial stress points plot between contours 0.10 and 0.30 . For application in situ, the current state of sand, that is the vertical and horizontal effective stress, and the void ratio, can be determined from published interpretations of cone

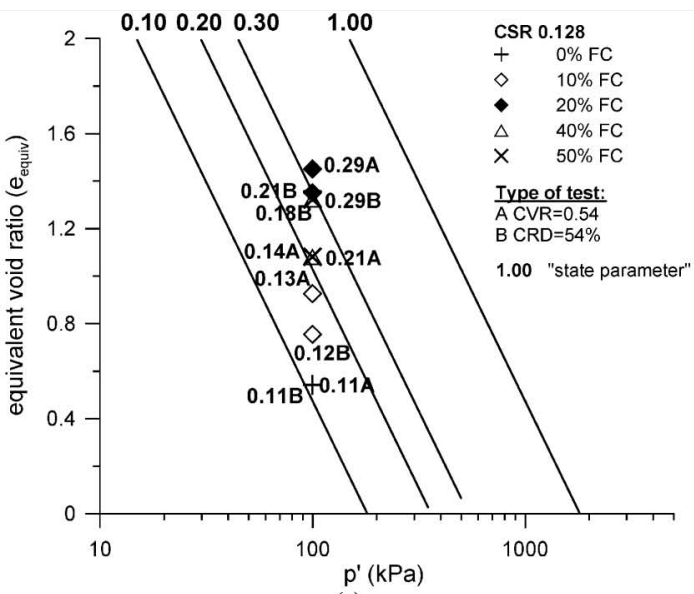

(a)

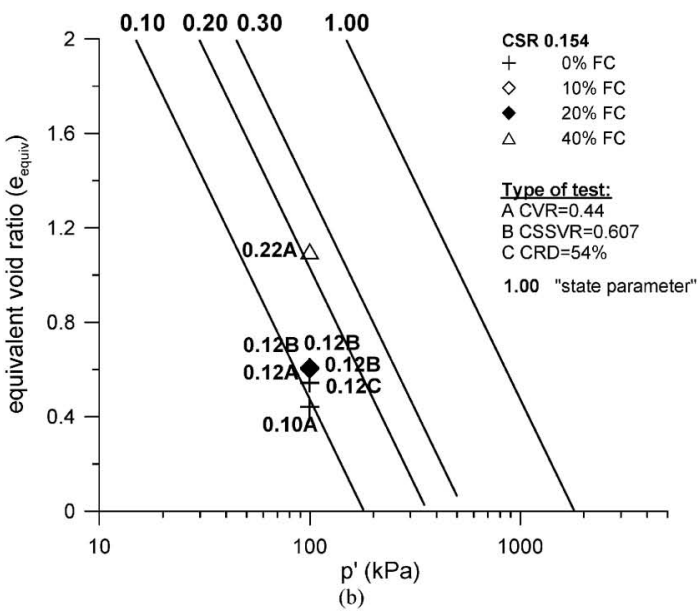

Fig. 11. Initial states for cyclic loading tests, in a plot of normalised equivalent void ratio against $\ln p^{\prime}$ : (a) tests at $\mathrm{CSR}=\mathbf{0 . 1 2 8}$, (b) tests at $\mathrm{CSR}=0.154$

penetration test data (e.g., Been et al., 1988; Houlsby and Hitchman, 1988).

\section{RESULTS}

Traditionally, the influence of fines content on the cyclic resistance ratio (CRR) of a silty soil has been studied by carrying out tests at constant void ratio, at constant sand skeleton void ratio, or at constant relative density, exclusive of each other, and results are usually plotted in terms of cyclic resistance ratio against silt content (e.g., Polito and Martin, 2001; Sadek and Saleh, 2007). Instead, Fig. 12 shows the results for all the tests that were analysed, which were performed at constant $e$, constant $e_{\mathrm{s}}$ and constant relative density. These are plotted as the logarithm of the cyclic resistance ratio, CRR, against the $\operatorname{logarithm}$ of the stress state parameter, $\log p^{\prime} / p_{\mathrm{cs}}^{\prime}$. For a given cyclic stress ratio, there is some evidence that the cyclic resistance ratio is related to the stress state parameter, independently of the fines content. Because of the approximation in the normalising parameter explained above, the data are slightly scattered, and it is thought that by using more refined definitions of $e_{\mathrm{s}}$ and $e_{\mathrm{f}}$ 


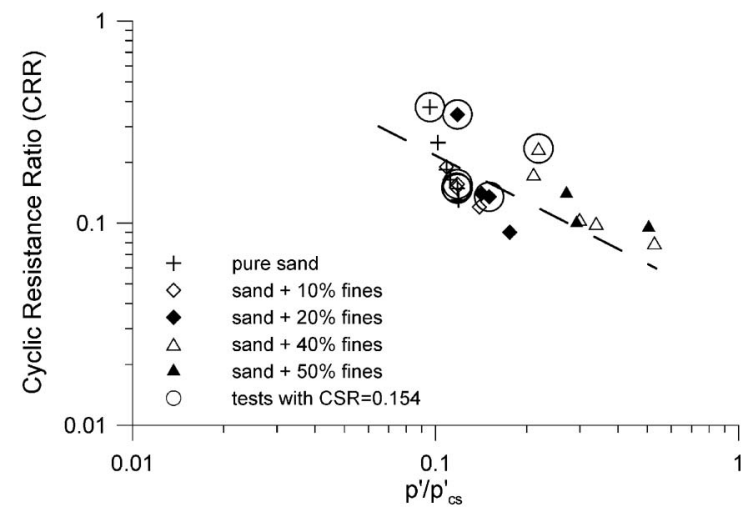

Fig. 12. Cyclic resistance ratio as function of stress state parameter for different fines contents in tests at $\mathbf{C S R}=\mathbf{0 . 1 2 8}$ (except circled tests, performed at $\operatorname{CSR}=0.154$ )

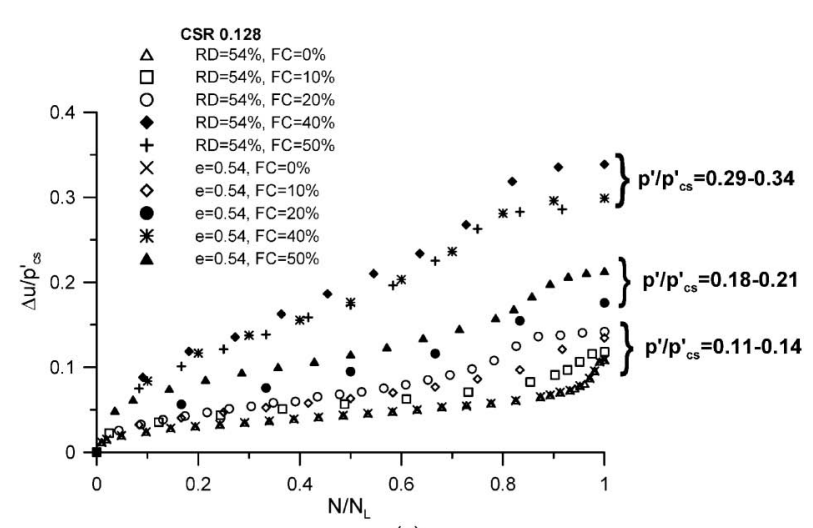

(a)

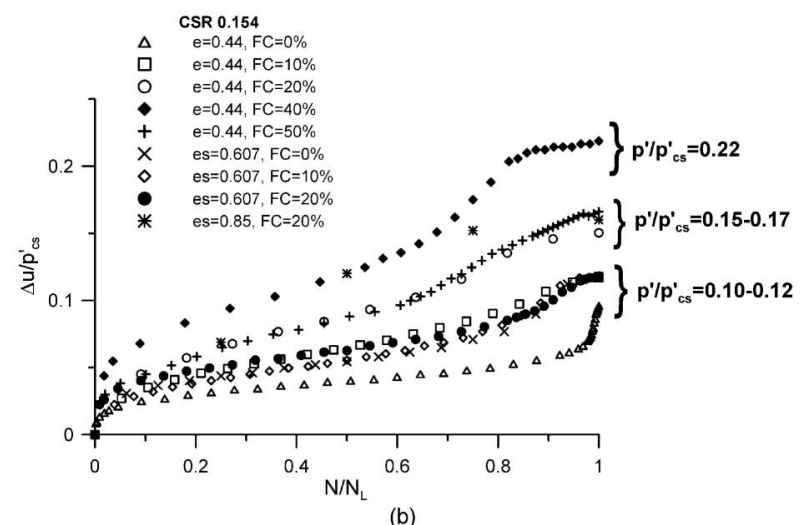

Fig. 13. Change in pore water pressure, $\Delta u$, normalised for the corrected inter-grain volume, against normalized number of cycles: (a) tests at $\mathrm{CSR}=0.128$, (b) tests at $\mathrm{CSR}=\mathbf{0 . 1 5 4}$

the relationship would be improved.

The pore water pressure development is generally plotted as pore water pressure ratio, $\Delta u / \sigma_{3}^{\prime}$, against number of cycles $(N)$ or normalised number of cycles $\left(N / N_{\mathrm{L}}\right)$. In Fig. 13, the pore water pressure has been normalised using the equivalent pressure, $p_{\mathrm{cs}}^{\prime}$, on the normalised CSL. The data, plotted separately for different cyclic stress ratios but otherwise showing all the different tests (constant $e$, constant $e_{\mathrm{s}}$, constant relative density) together, seem to group into bands, depending on the initial stress state

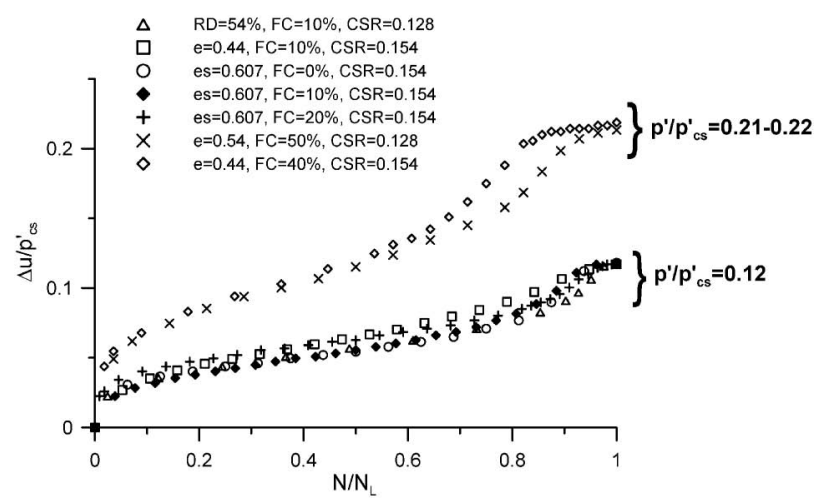

Fig. 14. Change in pore water pressure, normalised for inter-grain volume, against normalized number of cycles, for all tests carried out at $\operatorname{CSR}=0.128$ and $\mathrm{CSR}=0.154$

parameter at the start of cycling. For example, in Fig. 13(a), the data for values of $p^{\prime} / p_{\mathrm{cs}}^{\prime}=0.29-0.34$ plot in a narrow band, well above the data for lower values of stress state parameter, or in Fig. 13(b), the data for $p^{\prime} / p_{\text {cs }}^{\prime}$ $=0.15-0.17$ are almost coincident, but distinct from the data for other values of $p^{\prime} / p_{\mathrm{cs}}^{\prime}$.

In Fig. 14, the pore water pressure generation during tests started at initial stress states $p^{\prime} / p_{\mathrm{cs}}^{\prime}=0.12$, and $p^{\prime} / p_{\mathrm{cs}}^{\prime}$ $=0.21-0.22$, is re-plotted, not separating the data on the basis of the cyclic stress ratio used during testing. Clear bands are formed, again characterised by the values of initial stress state parameter and independent of the value of cyclic stress ratio. However, because the difference between the cyclic stress ratios used is not too large, these tests may not reflect fully the effects of the CSR on the pore water pressure generation.

The normalised pore water pressure, $\Delta u / p_{\mathrm{cs}}^{\prime}$, has now been re-plotted against the stress state parameter, $p^{\prime} / p_{\mathrm{cs}}^{\prime}$, for all tests (Fig. 15). Different symbols have been used for each cycle, in order to identify any potential trend. The cycles are defined on the graph by the value $N / N_{\mathrm{L}}$, with values varying between 0.05 (first cycle) and 1 (liquefaction). Straight lines have been fitted, which pass through the origin, with good coefficients of correlation, between 0.925 and 0.955 , except for the data for $N / N_{\mathrm{L}}=$ 0.05 , which corresponds to the first cycle and is more scattered, and for cycles close to liquefaction $\left(N / N_{\mathrm{L}}\right.$ $>0.80)$. In the first cycle, the data lie outside the band proposed by Lee and Albaisa (1974), with values typically between two and three times higher. Ahmedabad sand is a rather fine sand which particle size distribution falls within the range of distributions of most liquefiable sands defined by Tsuchida (1970), and therefore excess pore pressure may have developed more rapidly than would be seen in other coarser sands. On the other hand, the relative stiffnesses of the specimen and apparatus at the early stages of shearing could also have affected the results in the early stages of the tests. At low cycles and towards liquefaction the pore pressure generated is dictated by the boundary conditions (no pore water generated at $N / N_{\mathrm{L}}=$ 0 and liquefaction at $N / N_{\mathrm{L}}=1$ ). In Fig. 15, the data for the cycle ratios outside the 0.1-0.8 range show indeed 


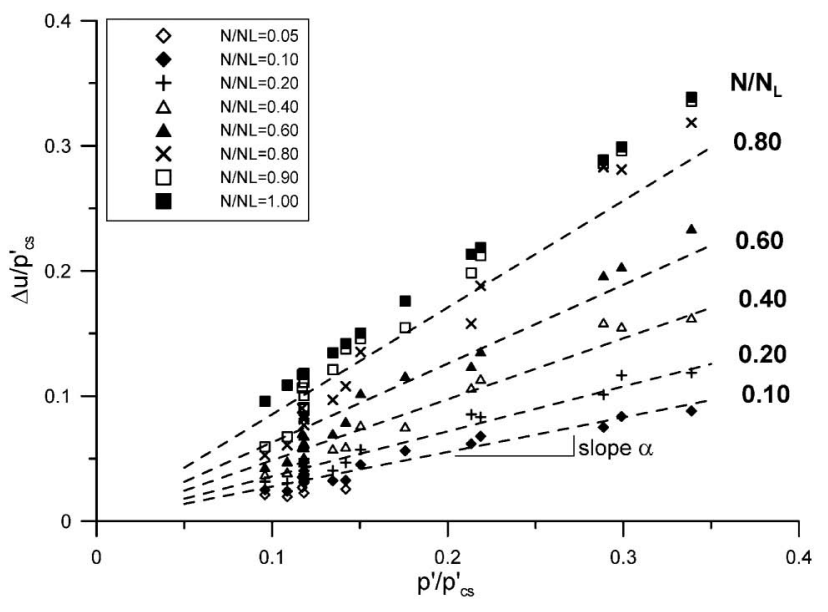

Fig. 15. Variation in normalised pore water pressure with the stress state parameter at different values of $N / N_{\mathrm{L}}$

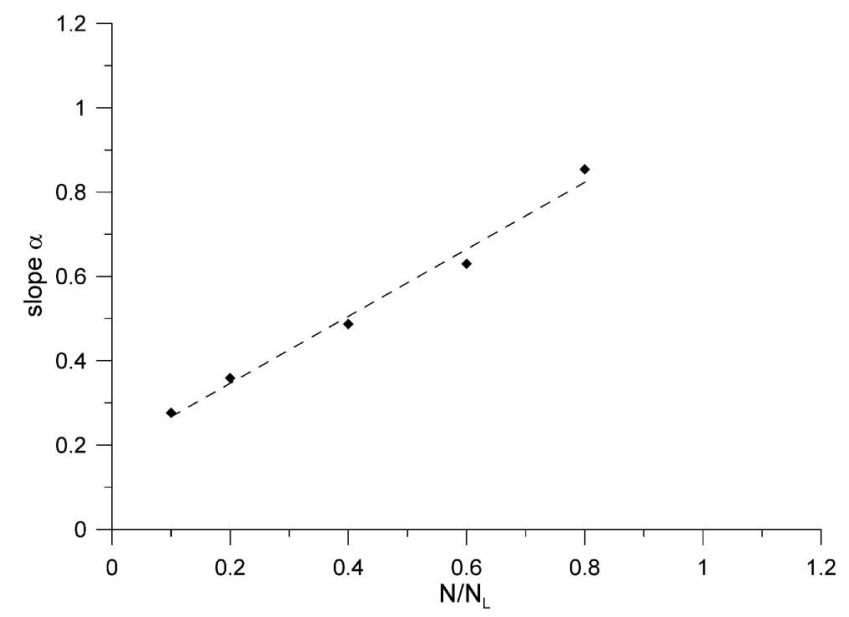

Fig. 16. Relationship between the slope of the trend lines in Fig. 15 and the values of $N / N_{\mathrm{L}}$

more scatter and it would have been difficult to fit a straight line with a good correlation coefficient. It is however interesting to note that for each cycle, the values of slope $\alpha$ of these lines, when plotted against the values of $N / N_{\mathrm{L}}$ within the range $0.1-0.8$ (Fig. 16), define a straight line, implying that there may be a simple relationship between the generation of pore water pressure, when normalised by the stress state parameter, and the number of cycles.

\section{CONCLUSIONS}

Data from cyclic loading tests on sand-fines mixtures have been presented so that the cyclic resistance ratio and pore water generation were shown to depend strongly on the stress state at the start of testing, irrespective of the type of testing. This paper showed a novel approach to analysing cyclic test data for sand-fines mixtures, by normalising these data with respect to state. This is similar to what had been successfully applied to plain sands by others, with the important difference that the reference line for normalising must take account of the fines content. Simple definitions of equivalent void ratio, which take account of fines content, have been used. The results presented therefore reflect the simplicity of the definitions adopted. They are nevertheless encouraging in showing the importance of state for quantifying the cyclic resistance and pore water pressure generation during cyclic loading of sand-fines mixtures, rather than fines content only. There exist more refined versions of equivalent void ratios that may refine the findings presented here, but they would require more time-consuming initial work on the identification of a reference normalised Critical State Line.

\section{ACKNOWLEDGEMENTS}

The work reported in this technical paper was carried out with financial assistance through sponsorship from the Ministry of Earth Sciences, formerly Department of Science and Technology (Seismology Division), Ministry of Science and Technology, Government of India, New Delhi. The authors gratefully acknowledge the support provided by the Ministry.

\section{REFERENCES}

1) American Society for Tests and Materials (ASTM): Standard Test Method for Load Controlled Cyclic Triaxial Strength of Soil, ASTM D 5311-92 (Re-approved 1996), ASTM, West Conshohocken, $\mathrm{Pa}$.

2) Amini, F. and Qi, G. Z. (2000): Liquefaction testing of stratified silty sands. Journal of Geotechnical and Geoenvironmental Engineering, ASCE, 126(3), 208-217.

3) Been, K., Cooks, J. H. A. and Jefferies, M. G. (1988): Interpretation of material state from the CPT in sands and clays. Proc. Conference on Penetration Testing, Institution of Civil Engineers, London, 215-218.

4) Been, K. and Jefferies, M. G. (1985): A state parameter for sands, Géotechnique, 35(2), 99-112.

5) Brandon, T. L., Rose, A. T. and Duncan, J. M. (2006). Drained and undrained strength interpretation of low-plasticity silts, Journal of Geotechnical and Geoenvironmental Engineering, ASCE, 132(2), 250-257.

6) Chang, N. Y., Yeh, S. T. and Kaufman, L. P. (1982): Liquefaction potential of clean and silty sands, Proc. 3rd International Conference on Earthquake Microzonation, 2, 1017-1032.

7) Coop, M. R. and Atkinson, J. H. (1993). The mechanics of cemented carbonate sands, Géotechnique, 43(1), 53-67.

8) Coop, M. R. and Lee, I. K. (1993): The behaviour of granular soils at elevated pressures, Proc. Wroth Memorial Symposium: Predictive Soil Mechanics, Thomas Telford, London, 186-198.

9) Dash, H. K. (2008): Undrained cyclic and monotonic response of sand-silt mixtures, $P h D$ thesis, Indian Institute of Science, Bangalore, India.

10) Dash, H. K. and Sitharam, T. G. (2009): Undrained cyclic pore pressure response of sand-silt mixtures: effect of nonplastic fines and other parameters, J. Geotech. and Geolog. Eng., DOI 10.1007/s10706-009-9252-5, http://dx.doi.org/[DOI]

11) Erten, M. H. and Maher, D. (1995): Cyclic undrained behavior of silty sand, Soil Dyn. Earthquake Eng., 14(2), 115-123.

12) Finn, W. D. L., Ledbetter, R. H. and Wu, G. (1994): Liquefaction in silty soils: Design and analysis, Ground Failures under Seismic Conditions, Geotechnical Special Publication (44), ASCE, New York, 51-76.

13) Haeri, S. M. and Hamidi, A. (2005): Steady state and liquefaction 
characteristics of gravelly sands, Journal of Geotechnical and Geological Engineering, 23, 141-156.

14) Hazirbaba, K. (2005): Pore pressure generation characteristics of sands and silty sands: A strain approach, PhD thesis, University of Texas, Austin, USA.

15) Houlsby, G. T. and Hitchman, R. (1988): Calibration chamber tests of a cone penetrometer in sand, Géotechnique, 38(1), 39-44.

16) Hyodo, M., Hyde, A. F. L., Aramaki, N. and Nakata, Y. (2002): Undrained monotonic and cyclic shear behaviour of sand under low and high confining stresses, Soils and Foundations, 42(3), 63-76.

17) IS Codes (Bureau of Indian Standards) IS: 1498-1970 "Classification and identification of soils." (1992) IS: 2720 (Part 3) Section 1-1980. "Specific gravity-fine grained soils.", (1992) (Part 14)-1983. " Determination of density index (relative density) of cohesionless soils.",

18) Kenny, T. C. (1977): Residual strength of mineral mixtures, Proc. 9th International Conference on Soil Mechanics and Foundation Engineering, Tokyo, 1, 155-160.

19) Klotz, E. U. and Coop, M. R. (2001): An investigation of the effect of soil state of the capacity of driven piles in sands, Geotechnique, 51(9), 733-751.

20) Kuerbis, R., Negussey, D. and Vaid, Y. P. (1988): Effect of gradation and fines content on the undrained response of sand, Proc. on Hydraulic Fill Structures, Geotechnical Special Publication (21), ASCE, 330-345.

21) Lade, V. P. and Yamamuro, J. A. (1997). Effects of nonplastic fines on static liquefaction of sands, Canadian Geotechnical Journal, 34, 918-928.

22) Lee, K. L. and Albaisa, A. (1974): Earthquake-induced settlement in saturated sands, J. Soil Mech. Found. Div., ASCE, 100, 387-406.

23) Martins, F. B., Bressani, L. A., Coop, M. R. and Bica, A. V. D. (2001): Some aspects of the compressibility behaviour of a clayey sand, Canadian Geotechnical Journal, 38, 1177-1186.

24) Monkul, M. M. and Ozden, G. (2006): Compressional behaviour of clayey sand and transition fines content, Engineering Geology, 96, (1-2), 105-106

25) Nocilla, A., Coop, M. R. and Colleselli, F. (2006): The mechanics of an Italian silt: an example of "transitional" behaviour, Géotechnique, 56(4), 61-71.

26) Polito, C. P. (1999): The effects of non-plastic and plastic fines on the liquefaction of sandy soils, PhD thesis, Virginia Polytechnic Institute and State University, USA.

27) Polito, C. P. and Martin II, J. R. (2001): Effects of nonplastic fines on the liquefaction resistance of sands, Journal of Geotechnical and Geoenvironmental Engineering, 127(5), 408-415.

28) Quadimi, A. and Coop, M. R. (2007): The undrained cyclic behaviour of a carbonate sand, Géotechnique, 57(9), 739-750.
29) Ravishankar, B. V. (2006): Cyclic and monotonic undrained behavior of sandy soils, $P h D$ thesis, Indian Institute of Science, Bangalore, India.

30) Sadek, S. and Saleh, M. (2007): The effect of carbonaceous fines on the cyclic resistance of poorly graded sands, Journal of Geotechnical and Geological Engineering, 25, 257-264.

31) Singh, S. (1994): Liquefaction characteristics of silts, Ground Failure Under Seismic Conditions, Geotechnical Special Publication (44), American Society of Civil Engineers, 105-116.

32) Thevanayagam, S. (2000): Liquefaction potential and undrained fragility of silty soils, Proc. 12th World Conference on Earthquake Engineering, Auckland, New Zealand, 8.

33) Thevanayagam, S. and Mohan, S. (1998): Intergranular void ratiosteady state strength relations for silty sands, Geotechnical Earthquake Engineering and Soil Dynamics III, Geotechnical Special Publication (75), ASCE, 349-360.

34) Tsuchida, H. (1970): Prediction and counter measure against liquefaction in sand deposits, Abstract of the Seminar at the Port and Harbor Research Institute, 3.1-3.33.

35) Ueng, T. S., Sun, C. W. and Chen, C. W. (2004): Definition of fines and liquefaction resistance of Maoluo river soil, Soil Dynamics and Earthquake Engineering, 24, 745-750.

36) Vaid, Y. P. (1994): Liquefaction of silty soils, Ground Failure Under Seismic Conditions, Geotechnical Special Publication (44), ASCE, 1-16.

37) Vaid, Y. P., Sivathayalan, S. and Stedman, D. (1999): Influence of specimen-reconstituting method on the undrained response of sand, Geotechnical Testing Journal, GTJODJ, 22(3), 187-195.

38) Wroth, C. P. and Bassett, R. H. (1965): A stress-strain relationship for the shearing behaviour of a sand, Géotechnique, 15(1), 32-56.

39) Xenaki, V. C. and Athanasopoulos, G. A. (2003): Liquefaction resistance of sand-silt mixtures: an experimental investigation of the effect of fines, Soil Dynamics and Earthquake Engineering, 23, 183-194.

40) Yamamuro, J. A. and Lade, P. V. (1997): Static liquefaction of very loose sands, Canadian Geotechnical Journal, 34, 905-917.

41) Yamamuro, J. A. and Kovert, K. M. (2001): Monotonic and cyclic liquefaction of very loose sands with high silt content, Journal of Geotechnical and Geoenvironmental Engineering, 127(4), 314-324.

42) Youd, T. L., Idris, I. M., Andrus, R. D., Arango, I., Castro, G., Christian, J. T., Dobry, R., Finn, W. D. L., Harder, L. F., Hynes, M. E., Ishihara, K., Koester, J. P., Liao, S. S. C., Marcuson, W. F., Martin, G. R., Mitchell, J. K., Moriwaki, Y., Power, M. S., Robertson, P. K., Seed, R. B. and Stoke, K. H. (2001): Liquefaction resistance of soils: summary report from the 1996 NCEER and 1998 NCEER/NSF workshops on evaluation of liquefaction resistance of soils, Journal of Geotechnical and Geoenvironmental Engineering, ASCE, 127(4), 297-313. 